\title{
Manganese Enhanced MRI for Use in Studying Neurodegenerative Diseases
}

\author{
Galit Saar* and Alan P. Koretsky* \\ Laboratory of Functional and Molecular Imaging, National Institute of Neurological Disorders and Stroke (NINDS), National \\ Institutes of Health, Bethesda, MD, United States
}

MRI has been extensively used in neurodegenerative disorders, such as Alzheimer's disease (AD), frontal-temporal dementia (FTD), mild cognitive impairment (MCl), Parkinson's disease (PD), Huntington's disease (HD) and amyotrophic lateral sclerosis (ALS). MRI is important for monitoring the neurodegenerative components in other diseases such as epilepsy, stroke and multiple sclerosis (MS). Manganese enhanced MRI (MEMRI) has been used in many preclinical studies to image anatomy and cytoarchitecture, to obtain functional information in areas of the brain and to study neuronal connections. This is due to $\mathrm{Mn}^{2+}$ ability to enter excitable cells through voltage gated calcium channels and be actively transported in an anterograde manner along axons and across synapses. The broad range of information obtained from MEMRI has led to the use of $\mathrm{Mn}^{2+}$ in many animal models of neurodegeneration which has supplied important insight into brain degeneration in preclinical studies. Here we provide a brief review of MEMRI use in neurodegenerative diseases and in diseases with neurodegenerative components in animal studies and discuss the potential translation of MEMRI to clinical use in the future.

Edited by: Makoto Osanai, Tohoku University, Japan

Reviewed by: Hironaka Igarashi, Niigata University, Japan Jon Shah,

Forschungszentrum Jülich, Germany

*Correspondence: Galit Saar saarg@mail.nih.gov

Alan P. Koretsky koretskya@ninds.nih.gov

Received: 17 September 2018 Accepted: 10 December 2018

Published: 07 January 2019

Citation:

Saar $G$ and Koretsky AP (2019) Manganese Enhanced MRI for

Use in Studying Neurodegenerative

Diseases.

Front. Neural Circuits 12:114. doi: 10.3389/fncir.2018.00114
Keywords: manganese, MEMRI, neurodegeneration, neuronal connectivity, tract tracing, manganese-52, molecular imaging

\section{INTRODUCTION}

MRI is in widespread use for diagnosis of neurological disorders, for monitoring the progression of disease, response to therapy, and for use in research. MRI is in active development for all diseases that have a neurodegenerative component. This includes the diseases that are primarily neurodegenerative such as Alzheimer's disease (AD), other forms of dementia such as frontal-temporal dementia (FTD) and mild cognitive impairment (MCI), Parkinson's disease (PD), Huntington's disease (HD), and amyotrophic lateral sclerosis (ALS). In addition, MRI is used for the neurodegenerative components of diseases such as epilepsy, stroke and multiple sclerosis (MS) that are not primarily caused by neurodegenerative processes. MRI applications to neurological diseases can be broadly characterized as those where the brain changes have large effects on MRI and can be used for diagnosis, medical decisions and trials with small numbers of participants. These studies rely on well-established MRI contrast mechanisms including enhancement in $T_{1}$ or $T_{2}$ weighted MRI, enhancement with gadolinium-based contrast agents, diffusion/perfusion techniques and fMRI techniques. For example, diffusion MRI is sensitive to early tissue damage due to ischemia which can influence treatment decisions, whereas long-term injury to tissue due to stroke can be measured with $\mathrm{T}_{1}$ or $\mathrm{T}_{2}$ based MRI contrast (Yoo et al., 2009; Merino and Warach, 2010). Blood brain barrier (BBB) breakage, detected due to leak of gadolinium-based agents, due to inflammation 
caused by MS is used to quantify the number of active lesions which progress to chronic lesions in $\mathrm{T}_{1}$ or $\mathrm{T}_{2}$ based MRI after extensive tissue damage (Traboulsee et al., 2016; Reich et al., 2018). MRI contrast has been useful for localizing sites of tissue damage, and to guide surgery for epilepsy, while fMRI has been used to map functional areas such as language to guide these surgeries (Duncan et al., 2016).

MRI has been less successful for diagnosis or treatment decisions in individuals for most of the primarily neurodegenerative diseases. In these cases, MRI has been extremely useful for research or as a way to decrease number of patients required in large trials where MRI can be an additional biomarker. Quantitative anatomical studies have been most useful in these cases. Hippocampal atrophy and ventricular enlargement have been associated with $\mathrm{AD}$ and MCI (Jack et al., 2004; Thompson et al., 2004; Ridha et al., 2008; Tang et al., 2014). Cortical thinning has been demonstrated by MRI in a number of neurodegenerative disorders such as HD (Nopoulos et al., 2010; Nanetti et al., 2018). The growing sensitivity of MRI due to increasing field strength and better detectors is allowing studies to be done at resolutions below $0.125 \mathrm{~mm}^{3}(0.5 \mathrm{~mm}$ linear resolution). Smaller volumes of hippocampal subfields such as the subiculum, CA1, CA3 and dentate gyrus (DG), have been measured in Alzheimer's patients compared to MCI and healthy patients (Kerchner et al., 2010; Mueller et al., 2010; Wisse et al., 2014). Significant reduction in the olfactory bulb (OB) have also been reported in $\mathrm{AD}$ and $\mathrm{PD}$ patients (Thomann et al., 2009; Wang et al., 2011). In PD, changes in substantia nigra (SN) due to neurodegeneration have been reported (Kwon et al., 2012; Lehéricy et al., 2014) and changes in the striatum volume have been studied in HD (Ross et al., 2014). In patients with ALS, high resolution MRI has detected anatomical changes in primary motor cortex and cortical spinal tract (Cosottini et al., 2016). While these high-resolution studies offer tremendous potential for moving to analyzing small numbers of patients the effect sizes have not been large enough to enable MRI to contribute to diagnosis and response to therapy in individuals. Therefore, there is a need to develop other strategies to enable MRI to detect processes associated with neurodegeneration. Manganese enhanced MRI (MEMRI) has now been used in a large number of preclinical studies in animal models of neurodegeneration. Here we present a brief review of this work and discuss the prospects for translating this type of contrast to humans.

MEMRI has been used to image anatomy and cytoarchitecture, obtain functional information from different areas of the brain, and to trace neural connections and axonal transport rates. All of this relies on the fact that $\mathrm{Mn}^{2+}$ is essential for brain health and on the rich and complex biology that the brain uses to move $\mathrm{Mn}^{2+}$. Brain architecture at the level of cytoarchitecture has been imaged with MRI including layer specific accumulation in the OB, cortex, hippocampus, retina, and cerebellum after systemic administration (Watanabe et al., 2002; Aoki et al., 2004; Lee et al., 2005; Berkowitz et al., 2006; Silva et al., 2008). Clear cytoarchitectural boundaries for different brain areas have been identified using MEMRI. Under the right conditions increased neural activity in a specific area can lead to increased accumulation of $\mathrm{Mn}^{2+}$ and contrast on
MRI. Sensory, motor, auditory, hypothalamic, and hippocampal activity have been reported from MEMRI (Lin and Koretsky, 1997; Aoki et al., 2002; Morita et al., 2002; Hsu et al., 2007; Yu et al., 2008; Eschenko et al., 2010; Hankir et al., 2012). A third type of information can be obtained from direct injection of $\mathrm{Mn}^{2+}$ into specific areas of the brain where $\mathrm{Mn}^{2+}$ will move in an anterograde direction along the direction of information flow to enable neuronal tracing studies (Pautler et al., 1998). $\mathrm{Mn}^{2+}$ will move transsynaptically allowing circuits to be mapped. With direct application strategies, MEMRI has been used to trace sensory pathways such as olfactory, visual, somatosensory, and auditory pathways. This can be done at the level of specific cytoarchitectural elements such as individual olfactory glomeruli, or specific cortical laminae (Pautler et al., 1998; Watanabe et al., 2001; Van der Linden et al., 2002; Allegrini and Wiessner, 2003; Leergaard et al., 2003; Cross et al., 2004; Murayama et al., 2006; Canals et al., 2008; Chuang and Koretsky, 2009; Tucciarone et al., 2009). Other pathways such as descending motor pathways and basal ganglia (BG)-striatal pathways have been imaged as well (Saleem et al., 2002; Pautler et al., 2003; Murayama et al., 2006). For detailed review on MEMRI procedures please see Silva et al. (2004). This broad range of information from MEMRI has led to its application in animal models of neurodegeneration, supplying important information about brain degeneration in preclinical studies.

\section{MEMRI IN ANIMAL MODELS OF NEURODEGENERATION}

\section{Studies Using Systemic Administration of Manganese}

Animal models of neurodegenerative diseases have been used in many MEMRI studies, that were mainly focused on either anatomy and cytoarchitecture changes that relates to disease symptoms and pathology. Following systemic administration of manganese, contrast in the brain is achieved $24 \mathrm{~h}$ later (Aoki et al., 2004; Lee et al., 2005). This allows the detection of anatomical and laminar changes in the brain to assess degeneration.

In $\mathrm{AD}$, large scale neuronal loss due to amyloid- $\beta$ ( $\mathrm{A} \beta)$ plaque formation and the presence of neurofibrillary tangles (NFTs) occurs at late stages of the disease (Hardy and Selkoe, 2002). Animal models of AD are based on overexpression of either amyloid precursor protein (APP) or tau protein that leads to the formation of $A \beta$ plaques or NFTs, respectively. The rTg4510 mouse model of tauopathy, that express high levels of human tau and accumulates NFTs, is a model of both AD and FTD. Following systemic administration of $\mathrm{Mn}^{2+}$, impaired accumulation of $\mathrm{Mn}^{2+}$ was measured in the total hippocampus and its subregions, and the amygdala. These are structures that relate to memory formation deficits that were detected at early stages of tau formation (3 months of age; Fontaine et al., 2017). The $\mathrm{Mn}^{2+}$ accumulation in these regions was further reduced with increased tau pathology at older ages (5-10 months of age; Perez et al., 2013; Fontaine et al., 2017). The 5XFAD mouse model that overexpress APP and presenilin 1, showed 
increased signal intensity in the hippocampus at early stages of AD (2-5 months of age) compared to controls, while behavioral assays showed increased learning and memory impairment with mice age (Tang et al., 2016). MEMRI results are also consistent with glucose studies in $\mathrm{AD}$ mouse models where impaired uptake of glucose (either decreased or increased uptake) was reported at different ages in mice (Luo et al., 2012; Poisnel et al., 2012; Macdonald et al., 2014). EEG studies have detected abnormal spike activity in the hippocampus of $\mathrm{AD}$ mice prior to memory impairments, which may explain the underlying basis of MEMRI results (Palop et al., 2007; Kam et al., 2016). Indeed, the increased accumulation of $\mathrm{Mn}^{2+}$ in the 5XFAD mouse model at the early stages of $\mathrm{AD}$, may be related to these EEG changes. However, the manganese accumulation mechanisms are not yet fully understood, and it could be due to $\mathrm{Mn}^{2+}$ uptake with inflammation as there is a report of increased $\mathrm{Mn}^{2+}$ uptake with elevated inflammation in stroke (Kawai et al., 2010).

MEMRI also enables direct visualization of laminar specific neurodegeneration and its recovery with treatment. Olfactory dysfunction is an early symptom of AD (and other neurodegenerative diseases; Bacon et al., 1998). MEMRI study of an olfactory-based AD mouse model with overexpression of APP specifically in olfactory neurons was shown to detect laminar changes in the $\mathrm{OB}$ and this was used to follow neurodegeneration and recovery following systemic administration of manganese (Saar et al., 2015). In the OB, overexpression of humanized-APP resulted in the disruption of the bulb's laminar structure. There was decreased manganese enhancement in the glomerular layer and a decreased $\mathrm{OB}$ volume compared to control (Figures 1A,B). Turning off APP overexpression with doxycycline showed a significant increase in manganese enhancement of the glomerular layer after only 1 week (Figure 1C), with further recovery after 3 weeks of the bulb back to control.

$\mathrm{PD}$ is characterized by the loss of dopaminergic neurons in the pars compacta of the SNc that leads to activity changes in the BG nuclei. In animal models of PD, 1-methyl-4-phenyl-1,2,3,6tetrahydropyridine (MPTP) induces death of dopaminergic neurons in the SNc. Systemic administration of manganese in a PD rat model, 2 weeks after MPTP lesioning in the SNc was induced, resulted in decreased $\mathrm{Mn}^{2+}$ accumulation in the $\mathrm{SNc}$ and striatum, and hippocampal subregions compared to control rats due to degeneration of dopaminergic neurons. Increased accumulation was measured in the subthalamic nucleus (STN). Treatment of MPTP rats with ceftriaxone, was shown to prevent these changes (Weng et al., 2016). In studies with a PD mouse model of MPTP intoxication, $\mathrm{Mn}^{2+}$ enhancement was decreased in the $\mathrm{SNc}$ compared to control while the striatum showed increased $\mathrm{Mn}^{2+}$ enhancement after 2 days (Olson et al., 2016) and 1 or 2 weeks (Kikuta et al., 2015). In the striatum, the increased $\mathrm{Mn}^{2+}$ uptake, in the first few days after MPTP intoxication, was suggested to reflect high astroglial reactivity due to early striatum termini degeneration, which leads to increased signal enhancement (Olson et al., 2016). Thus, $\mathrm{Mn}^{2+}$ accumulation could be very dependent on timing with respect to cell death. Treatment with LBT-3627 (a VIPR2 agonist), prior to MPTP intoxication did not result in increased manganese enhancement in the SNc (Olson et al., 2016). These studies

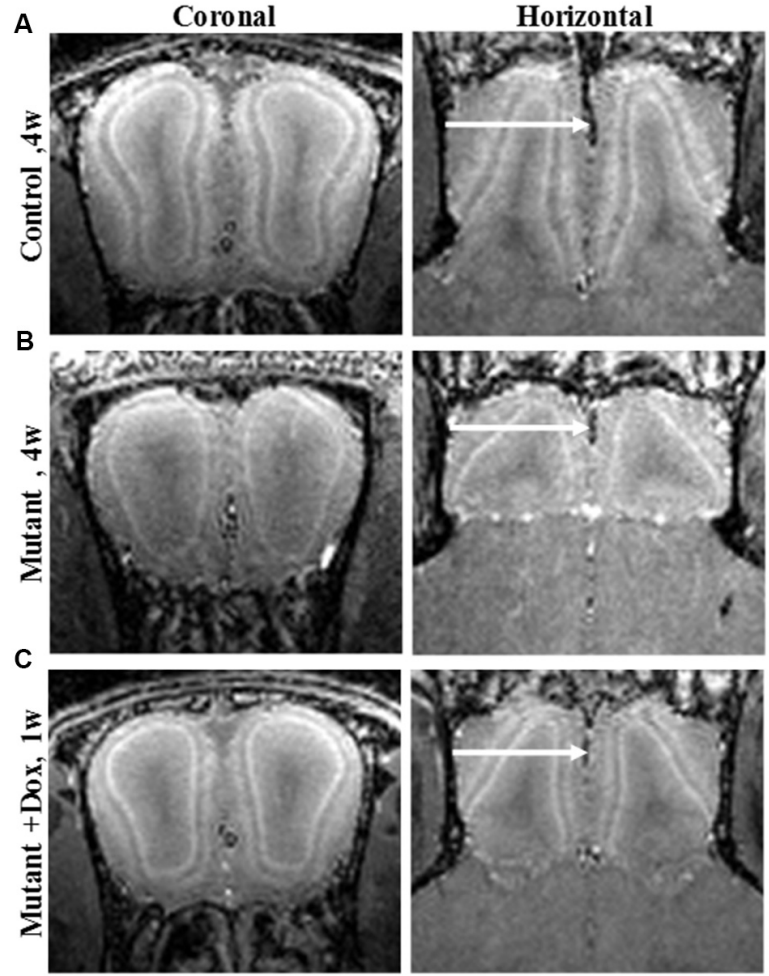

FIGURE 1 | Coronal and horizontal $T_{1}$ weighted images manganese enhanced MRI (MEMRI), at $50 \mu \mathrm{m}$ isotropic resolution, taken $24 \mathrm{~h}$ after iv infusion of $100 \mathrm{mM} \mathrm{MnCl}_{2}$ solution of 4-week-old (A) control, (B) mutant and (C) mutant mouse after 1 week of doxycycline treatment mice. Reprinted from Saar et al. (2015) with permission from Elsevier.

show that MEMRI is able to detect neurodegeneration but also enabled testing different reagents ability to block and/or reverse neuronal loss.

Systemic administration of manganese was also used to study neurodegenerative changes in animal models of retinal degeneration. Dark adapted royal college of surgeons (RCS) rats, a model of photoreceptor degeneration, underwent MEMRI before degeneration onset [developmental stage Postnatal day (P) 17] and during the course of degeneration, (P36 and P57, after the loss of rods and cones, respectively). The retinal thickness was significantly reduced only in the pathological stage, P57 rats, compared to age matched control rats. Decreased $\mathrm{Mn}^{2+}$ uptake was evident in the developmental stage (P17), prior to the onset of photoreceptor damage, throughout the retina, but increased at later ages. This was attributed to ionic dysregulation during pathological retinal thinning (Berkowitz et al., 2008).

\section{Neuronal Tracing Studies With MEMRI}

Direct injection of manganese into specific brain areas can be used to trace neuronal connections in the brain and allows for the detection of impaired intracellular transport. Thus, MEMRI can be used to study axonal transport and measure axonal transport rates in the rodent brain. In the Tg2576 AD mouse model, $\mathrm{A} \beta$ depositions were detected in the $\mathrm{OB}$ prior to other brain areas, which resulted in decreased olfactory function 
(Wesson et al., 2010). Intranasal administration of manganese showed that the axonal transport rates from the olfactory epithelium to the $\mathrm{OB}$ layers were decreased prior to $\mathrm{A} \beta$ plaque formation and continued to decrease with the progression of $\mathrm{A} \beta$ plaque formation in this mouse model (Smith et al., 2007; Wang et al., 2012). Similar results were obtained with an APP knockout (APP ${ }^{-/-}$) mouse model (Smith et al., 2010). A MEMRI study in a triple transgenic AD mouse model, reported decreased axonal transport in the olfactory system, that preceded $A \beta$ plaque deposition and also the formation of NFTs (Kim et al., 2011). In the APP knockout (APP ${ }^{-/-}$) mouse model, $\mathrm{Mn}^{2+}$ injection into CA3 region of the hippocampus, showed reduced $\mathrm{Mn}^{2+}$ transport from the hippocampus to the amygdala and basal forebrain and to the contralateral hippocampus (Gallagher et al., 2012). Intraocular injection of $\mathrm{Mn}^{2+}$ also revealed reduced $\mathrm{Mn}^{2+}$ transport in the visual system of those mice (Gallagher et al., 2012). Similar study of $\mathrm{Mn}^{2+}$ injection into the CA3 region of the hippocampus in APPSwInd transgenic mice, that express mutant APP with both Swedish and Indiana mutations, showed decreased $\mathrm{Mn}^{2+}$ transport along the hippocampus to basal forebrain pathway with ageing and altered $\mathrm{Mn}^{2+}$ accumulation in APPSwInd mice that displayed $A \beta$ plaques. This suggest that the natural alteration in neuronal connections with ageing is further disrupted with APP overexpression and the formation of $A \beta$ plaques (Bearer et al., 2018). In addition, MEMRI was used to assess therapeutic reagents and test their ability to improve axonal transport. Treatment with R-Flurbiprofen, that selectively reduce $A \beta 42$, and chronic treatment with MRK-560, a gammasecretase inhibitor, were shown to significantly improve axonal transport rates in Tg2576 mice (Smith et al., 2011; Wang et al., 2012).

In the rTg4510 mouse model of tauopathy, nasal administration of $\mathrm{Mn}^{2+}$ revealed axonal transport deficits in the $\mathrm{OB}$ in an age dependent manner starting at 3 months of age, prior to tau pathology (Majid et al., 2014). This is similar to other $\mathrm{AD}$ mouse models where axonal transport deficits preceded $\mathrm{A} \beta$ plaque formation in the brain. Moreover, a different mouse model of tauopathy, JNPL3, also measured impaired axonal transport of $\mathrm{Mn}^{2+}$ with increasing tau pathology (Bertrand et al., 2013).

Axonal transport of manganese was studied in a widely used ALS mouse model, the Tg SOD1-G93A, which is a model of severe neurodegeneration with selective loss of motor neurons and progressive motor weakness. Intranasal administration of manganese showed significantly slower transport rates in $\mathrm{OB}$ of ALS mice compared to control mice. Acute treatment with NAP (davunetide), a microtubule interacting compound that protects against tau pathology, resulted in similar axonal transport rates as for control mice in this mouse model of ALS (Jouroukhin et al., 2013).

Intraocular injection of manganese was used to follow retinal degeneration changes of P90 RCS rats, in which photoreceptors are already degenerated. Changes in the retina laminar structure were detected using MEMRI with the loss of three out of the seven layers detected in normal retina as well as significant retinal thinning (Nair et al., 2011).
MEMRI tracing after direct injection was also done in the unilateral 6-hydroxydopamine (6-OHDA) rat model of PD, where lesions are induced in the SNc. $\mathrm{Mn}^{2+}$ injection into the globus pallidus nucleus and SN of unilateral 6-OHDA showed increased transport across hemispheres in several structures such as the habenular complex ( $\mathrm{Hab})$, and the thalamic anteroventral compared to control rats (Pelled et al., 2007). This suggests a large degree of plasticity in this model of neurodegeneration. A later study used MEMRI to study the etiology of depression in $\mathrm{PD}$ with 6-OHDA rat model. Manganese injection to the raphe nuclei showed reduced raphe connectivity, following the loss of dopamine cells and enhanced connectivity in Hab, that was associated with depression like behavior. Apomorphine treatment, a dopamine replacement therapy, resulted in partial recovery in raphe connectivity (Sourani et al., 2012). In contrast to the previous studies, manganese injection into the STN of 6-OHDA rats in a different study, showed decreased axonal transport from ipsilateral STN to structures of BG, such as ventral pallidum compared to control rats (Soria et al., 2011).

Genetic mutations are associated with axonal transport impairment that is commonly found in neurodegenerative diseases, such as APP and tau in AD, SOD1 in ALS, huntingtin in HD and Parkin in PD (Millecamps and Julien, 2013). Indeed, decreased axonal transport rates in affected areas of the brain is a robust finding across a number of animal models of neurodegenerative diseases presented here. Axonal transport measurements using MEMRI gives unique information and would be an ambitious target for potential translation to humans.

\section{MEMRI IN DISEASES WITH NEURODEGENERATIVE COMPONENTS}

Although not defined as neurodegenerative diseases, MS, stroke, epilepsy, and glaucoma cause neurodegeneration in later stages. MS is an inflammatory disease of the central nervous system (CNS) and is characterized with lesions that can appear throughout the brain and in later stages with demyelinated axons and progressive neurodegeneration. In stroke, following the acute stage where an ischemic core is formed, the later stages are characterized with ongoing vascular impairment and neurodegeneration. Epilepsy is characterized by spontaneous recurrent seizures with the development of hippocampal sclerosis, neuronal cell loss, inflammation and neurodegeneration.

The most common type of stroke is the ischemic stroke. Animal models of ischemic stroke includes the middle cerebral artery occlusion (MCAO) and photothrombotic cortical injury (PCI). Systemic administration of manganese in rats and mice that undergo unilateral MCAO and PCI showed increased manganese accumulation in the perilesional tissue and reduced $\mathrm{Mn}^{2+}$ transport in the first few days after stroke was induced (Aoki et al., 2003; Hao et al., 2016; Chan et al., 2017). The increased $\mathrm{Mn}^{2+}$ uptake was attributed to inflammatory processes in the perilesional tissue (Kawai et al., 2010; Hao et al., 2016). This opens the possibility of using $\mathrm{Mn}^{2+}$ to measure inflammatory responses. It was also shown that 
the affected brain area with enhanced $\mathrm{Mn}^{2+}$ was smaller than the area that was detected with reduced apparent diffusion coefficient in diffusion MRI. This was interpreted to mean that MEMRI detects the ischemic core consistent with accumulation of $\mathrm{Mn}^{2+}$ being due to inflammation (Kawai et al., 2010).

Local injection of manganese into the brain was used to study connectivity in animal models of stroke. Manganese injection into sensorimotor cortex, 2 weeks after unilateral stroke induced by MCAO in rats, exhibited reduced and delayed manganese enhancement in the ipsilateral thalamus and SN which indicates loss of connectivity of areas in the sensorimotor cortex (van der Zijden et al., 2007, 2008; Hao et al., 2016). At later time points, 4 and 10 weeks after stroke, manganese enhancement was restored in ipsilateral sensorimotor cortex and increased enhancement was detected in the contralateral hemisphere that was correlated to functional recovery observed in behavioral tests (van der Zijden et al., 2008). The accumulation in the contralateral hemisphere was attributed to increased plasticity along the corpus callosum (CC). However, manganese injection into the contralateral primary motor cortex showed declined manganese enhancement into the ipsilateral sensorimotor cortex 10 weeks after stroke (van Meer et al., 2010). This result was explained by larger induced lesions and the different location of manganese injection in this study as compared to the earlier study.

MEMRI has also been used in animal models of MS. A common animal model for MS is experimental autoimmune encephalomyelitis (EAE), which uses active immunization with CNS homogenates, myelin, or myelin-derived antigens, that induce autoimmune mediated responses. As optic neuritis is one of the first symptoms of MS, MEMRI was used to assess axonal transport in the optic nerve $(\mathrm{ON})$ in EAE animal models. In an EAE rat model, systemic administration of $\mathrm{Mn}^{2+}$ showed increased signal enhancement in the ON compared to control rats $24 \mathrm{~h}$ after administration, that was correlated with the severity of axonal loss. The increase in $\mathrm{Mn}^{2+}$ might have been due to overload of intracellular $\mathrm{Ca}^{2+}$ in response to axonal damage in the ON (Boretius et al., 2008). In an EAE mouse model, following intraocular injection, $\mathrm{Mn}^{2+}$ accumulation as well as axonal transport rates were significantly decreased both in moderate and severe optic neuritis when compared to control mice. The degree of alteration in axonal transport was correlated to the extent of visual impairment and changes in axonal pathology (Lin et al., 2014). In another study, the EAE mouse model was used to follow changes in CC connectivity with MEMRI, as atrophy of CC is also observed in MS patients. Manganese was directly injected into the visual cortex and the CC was traced over time. An increase in manganese enhancement was detected in the CC compared to control mice in the first $14 \mathrm{~h}$ after $\mathrm{Mn}^{2+}$ injection in this study (Chen et al., 2008). It is not clear why an increase was detected in the CC, but it was suggested that it involved ion dyshomeostasis, due to increased intracellular $\mathrm{Ca}^{2+}$ accumulation.

Animal models of temporal lobe epilepsy includes the kainic acid (KA) and pilocarpine induced status epilepticus (SE) models that represent the acute phase of epilepsy. In the latent phase, animals are seizure free until the onset of spontaneous recurrent seizure in the chronic phase. These phases are associated with different neurobiological changes such as, hippocampal sclerosis, mossy fiber sprouting, inflammation and neurodegeneration. MEMRI studies after systemic administration of $\mathrm{Mn}^{2+}$, showed decreased signal intensity in the hippocampus that was attributed to decreased neuronal activity in a KA rat model (Alvestad et al., 2007; Immonen et al., 2008). Decreased manganese signal in the DG and CA3 was also detected in the acute phase of $30 \mathrm{~min}$ induced SE in the pilocarpine model, with the low signal related to edema and not to cell death (Malheiros et al., 2014). Increased manganese signal intensity in the DG and CA3 was detected later in the latent phase (Alvestad et al., 2007). In the chronic phase the epileptic rats showed increased signal intensity in the CA3 and DG compared to control rats. However, this increased MEMRI signal was correlated with mossy fiber sprouting and not with neurodegeneration (Immonen et al., 2008; Malheiros et al., 2012) and was not dependent on seizure frequency (Immonen et al., 2008). In a different rat model, where SE was induced by lithiumpilocarpine injection, MEMRI was used to assess mesenchymal stem cells (MSCs) treatment to reduce epileptogenesis in the hippocampus. In this study, higher manganese signal was detected in the DG and CA3 of vehicle treated epileptic rats compared to controls following systemic $\mathrm{Mn}^{2+}$ administration. The manganese enhancement was reduced in MSC infused rats and was associated with suppression of mossy fiber sprouting seen by histology in the MSC group (Fukumura et al., 2018).

In a MEMRI study of neuronal activation, increased manganese signal intensity was observed in the CA3 region of the hippocampus in the acute phase of KA-treated rats compared to control. Injection of diltiazem, an L-type calcium channel blocker, to KA-treated rats, resulted in attenuation of the manganese signal in the CA3 demonstrating an activity dependent uptake. This was correlated with decreased focal edema and decreased neuronal swelling observed by histology following diltiazem injection (Hsu et al., 2007). Direct injection of manganese into the entorhinal cortex of KA injected rats resulted in increased number of manganese enhanced pixels in the DG and CA3 compared to control rats. This increase was correlated to histological mossy fiber sprouting (Nairismägi et al., 2006). Direct $\mathrm{Mn}^{2+}$ injection into the lateral ventricle also resulted in increased manganese enhancement in the hippocampus, CA1 and DG, but was inversely correlated with seizure frequency (Dedeurwaerdere et al., 2013).

Glaucoma is characterized by progressive degeneration of retinal ganglion cells, that later effect structures along the visual pathway in the brain. Although not primarily a neurodegenerative disease, its main clinical impact is due to neurodegeneration. The DBA/2J mouse model is a late onset, hereditary glaucoma model associated with age dependent increase in intraocular pressure. MEMRI studies with DBA/2J mice showed changes in ocular anatomy due to glaucoma (Calkins et al., 2008) and decreased manganese enhancement in superior colliculus, $\mathrm{ON}$ and lateral geniculate nucleus compared 
to control mice that was further decreased with age (Fiedorowicz et al., 2018; Yang et al., 2018). Similar results were obtained in an induced ocular hypertension rat model of chronic glaucoma, where decreased $\mathrm{Mn}^{2+}$ enhancement in the $\mathrm{ON}$ of the glaucomatous eye was observed after intravitreal injection (Chan et al., 2008).

\section{TRANSLATING MEMRI TO HUMANS}

The large number of studies that have used $\mathrm{Mn}^{2+}$ as a contrast agent in neurodegenerative diseases to assess both anatomical and neuronal connectivity changes in preclinical studies, makes it interesting to determine if it may be possible to apply MEMRI to humans. Unfortunately, the potential use of $\mathrm{Mn}^{2+}$ as a contrast agent in human studies of neurodegeneration is limited by toxicity. Most of the animal studies are done at doses that might be hard to justify in humans (Chandra and Shukla, 1976; Wolf and Baum, 1983; Crossgrove and Zheng, 2004). In the past, mangafodipir (MnDPDP, Teslascan), an FDA-approved chelated $\mathrm{Mn}^{2+}$ contrast agent was used in clinical studies to image healthy volunteers and patients with liver metastases, pancreatic cancer, and myocardial infarction (Wang et al., 1997; Federle et al., 2000; Schima et al., 2002; Skjold et al., 2007). The specific tissue contrast is due to release of $\mathrm{Mn}^{2+}$ from the chelate due to transmetalation with zinc in the blood. However, the FDA-approved label indication for liver metastases detection did not warrant further production and it is not widely available. Furthermore, FDA-approved doses are lower than used in animal studies of neurodegeneration. Nevertheless, animal studies have shown the potential usefulness of MnDPDP to study retinal degeneration (Olsen et al., 2008; Tofts et al., 2010). Unlike gadolinium-based agents, which are extracellular agents with rapid clearance that requires significant extracellular space to detect, the manganese signal enhancement is due to intracellular accumulation of $\mathrm{Mn}^{2+}$ that lasts in the tissue long after it is cleared from the blood. This property provides the unique contrast in the brain where cytoarchitecture, activity and neuronal tracing can be detected. Early studies with MnDPDP administration to healthy volunteers, showed increased $\mathrm{Mn}^{2+}$ enhancement in the choroid
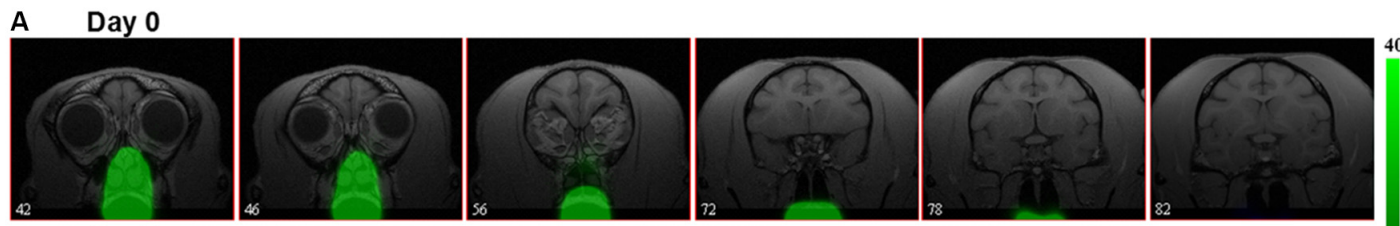

Day 7
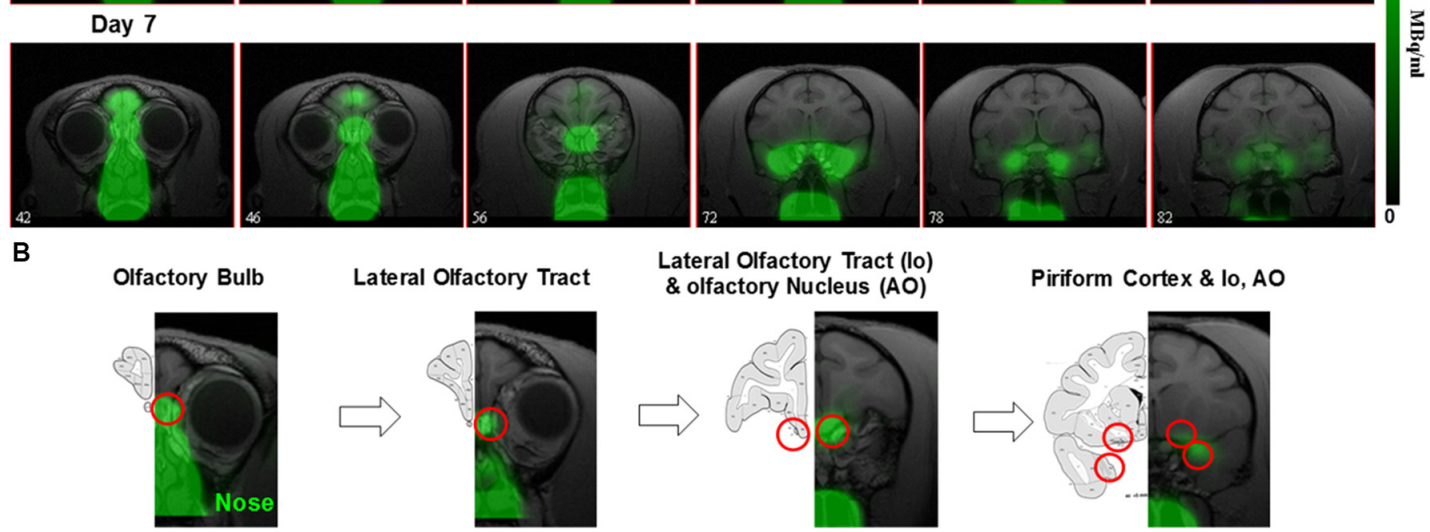

Piriform Cortex \& lo, AO
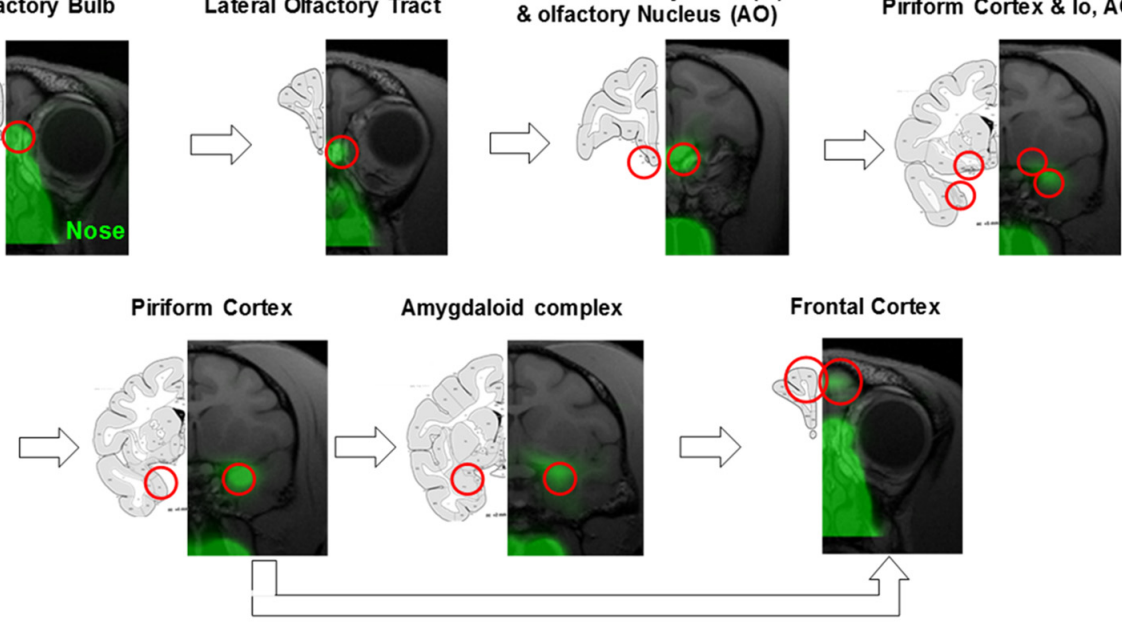

FIGURE $2 \mid{ }^{52} \mathrm{Mn}$ nasal administration in monkeys (A) positron emission tomography (PET) images co-registered with MRI images from front to back immediately after (day 0 ) and 7 days after nasal administration of ${ }^{52} \mathrm{Mn}^{2+} .{ }^{52} \mathrm{Mn}^{2+}$ solution of $7-22 \mathrm{MBq}(0.2-0.6$ mCi) was administered to both nostrils on day 0 (total volume $0.5 \mathrm{ml}$ ). Immediately after ${ }^{52} \mathrm{Mn}^{2+}$ administration the radioactivity is localized only to the nose area. By day 7 the ${ }^{52} \mathrm{Mn}{ }^{2+}$ traced into the brain from the nose to the amygdala. (B) Olfactory pathway in monkeys. PET images co-registered with MRI images following ${ }^{52} \mathrm{Mn}^{2+}$ administration into the nostrils and the corresponding monkey atlas images (Martin and Bowden, 2000). ${ }^{52} \mathrm{Mn}^{2+}$ administration to the nostrils traces the olfactory pathway from the nose to the olfactory bulb (OB), then to the olfactory tract, olfactory nucleus, piriform cortex, amygdala and the frontal cortex. Reprinted from Saar et al. (2018) with permission from Springer. 
plexus and pituitary gland, structures that lack a BBB (Wang et al., 1997; Sudarshana et al., 2018). It will be interesting to see if MnDPDP enhances the brain in human studies in cases where there is breakdown of the $\mathrm{BBB}$, due to $\mathrm{MS}$ and other disorders.

Parenteral nutrition contains manganese, making this a possible way to administer $\mathrm{Mn}^{2+}$. Signal enhancement in BG structures, mainly the globus pallidus, in $\mathrm{T}_{1}$ weighted images was reported. However, in these cases the patients received long-term parenteral nutrition ( $>1$ month), showed very high whole blood manganese concentrations and in some cases developed parkinsonian-like symptoms. No signal change was detected in the brain of control patients and low manganese exposure patients (Quaghebeur et al., 1996; Aschner et al., 2015; Livingstone, 2018). With these limitations, parenteral nutrition may be useful for some clinical applications of MEMRI. In the past, $\mathrm{MnCl}_{2}$ solution was given intravenously to healthy volunteers to study its safety and efficacy for cardiovascular imaging. Decreased myocardium $\mathrm{T}_{1}$ values were measured while no adverse events and good tolerance for $\mathrm{MnCl}_{2}$ were reported (Fernandes et al., 2011). This may allow the use of $\mathrm{MnCl}_{2}$ solution, at appropriate doses, for brain imaging in clinical studies.

Another approach would be to use radioactive $\mathrm{Mn}^{2+}$ to enable positron emission tomography (PET) studies rather than rely on MRI. Recent advances in preparation of high energy radiotracers allow for the production of two manganese radiotracers for PET imaging; manganese-51 $\left({ }^{51} \mathrm{Mn}\right)$ and manganese-52 $\left({ }^{52} \mathrm{Mn}\right)$ with half-lifes of $46 \mathrm{~min}$ and 5.6 days, respectively. As PET has higher sensitivity than MRI, a lower concentration of $\mathrm{Mn}^{2+}$ can be used for PET, that may enable its use in clinical studies to obtain information that has been shown to be useful in preclinical MEMRI studies. Indeed, manganese-54, a gammaemitter $\left({ }^{54} \mathrm{Mn}, t_{1 / 2}=312.5\right.$ days $)$ has been used to study manganese accumulation of tissues in the body of mice and monkeys (Dastur et al., 1971; Lydén et al., 1983) and has been used to visualize specific neuronal connections in rats (Sloot and Gramsbergen, 1994; Tjälve et al., 1996; Takeda et al., 1998). Due to its high gamma energy and long half-life ( $\sim 1$ year), ${ }^{54} \mathrm{Mn}$ is not likely to be clinically useful.

The half-life of 5.6 days, of the positron emitter ${ }^{52} \mathrm{Mn}$ allows its use in longitudinal biodistribution studies in the body and brain (Topping et al., 2013; Graves et al., 2015; Brunnquell et al., 2016; Hernandez et al., 2017; Napieczynska et al., 2017; Saar et al., 2018). MEMRI studies have shown that following systemic administration, the final distribution of manganese in the brain that allows anatomical structures was achieved $24 \mathrm{~h}$ after infusion. This makes ${ }^{52} \mathrm{Mn}$ a suitable radiotracer for imaging of brain anatomy and function. ${ }^{52} \mathrm{Mn}^{2+}$ infusion in rats showed manganese accumulation of the radiotracer in the head and brain with a similar contrast to that seen in MEMRI (Brunnquell et al., 2016; Saar et al., 2018).

The $\sim 6$ days half-life of ${ }^{52} \mathrm{Mn}$ should also allow neuronal tracing studies. Intranasal administration of ${ }^{52} \mathrm{Mn}^{2+}$ traces the olfactory pathway over the course of several days in monkeys (Figure 2; Saar et al., 2018) similar to MEMRI (Pautler et al., 1998; Chuang and Koretsky, 2009). Immediately after administration ${ }^{52} \mathrm{Mn}^{2+}$ radioactivity was localized in the nasal turbinates with no manganese accumulation in the brain. By 4 days later ${ }^{52} \mathrm{Mn}^{2+}$ could be traced to the amygdala and prefrontal areas of the cortex (Figure 2). Nepieczynska et al (Napieczynska et al., 2017) showed imaging of the dopaminergic and striatonigral pathways in rats $24 \mathrm{~h}$ after direct injection of ${ }^{52} \mathrm{Mn}^{2+}$ into the ventral tegmental area and the dorsal striatum, respectively. The ability of ${ }^{52} \mathrm{Mn}^{2+}$ to follow neuronal pathways after direct injection of the ${ }^{52} \mathrm{Mn}^{2+}$ PET tracer to a specific area in the brain similar to MEMRI, can be used to study all the neuronal pathways already studied with MEMRI such as the visual and BG pathways (Pautler et al., 1998; Watanabe et al., 2001; Murayama et al., 2006). Quantification of the axonal transport changes as has been done in MEMRI for animal models of neurodegenerative diseases should also be possible. Finally, the rise in usefulness of focused ultrasound to break the $\mathrm{BBB}$ in human should enable delivery of $\mathrm{Mn}^{2+}$ to any area of the human brain, as has already been shown in rodents (Howles et al., 2010). It is interesting that the manganese radiotracer ${ }^{52} \mathrm{Mn}^{2+}$ for PET imaging acts so similar to that of $\mathrm{Mn}^{2+}$ in MEMRI, even though the PET dose is $~ 2,000$-fold lower (Saar et al., 2018). The lower PET resolution may present a problem for using Mn-PET instead of MEMRI as it limits the ability to detect cytoarchitecture and small structures in the brain. However, the growing interest in PET/MRI systems may enable the use of Mn-PET with high resolution MRI image registration. These results demonstrates that ${ }^{52} \mathrm{Mn}^{2+}$ may be useful in human studies for imaging neurodegeneration by tracking changes in neuronal connections and anatomical changes at clinically safe doses.

\section{CONCLUSION}

In conclusion, there is a large growth of preclinical literature that has used MEMRI to study different aspects of neurodegeneration. Due to the wide variety of mechanisms that the brain uses for accumulation of $\mathrm{Mn}^{2+}$, care must be taken in assigning the cellular mechanism for any changes in MEMRI after systemic $\mathrm{Mn}^{2+}$ administration. However, tracing studies that use $\mathrm{Mn}^{2+}$ to measure changes in axonal transport have been more straightforward. MEMRI has been used to assess pharmacological treatments in animal models of neurodegeneration and can serve as a screening tool to identify potential therapeutics. Development of MRI agents that can be used at safe doses or use of PET manganese radiotracers might enable the translation of these exciting results to humans.

\section{AUTHOR CONTRIBUTIONS}

GS wrote the manuscript. AK proposed the topic and edited the manuscript.

\section{FUNDING}

This research was supported by the Intramural Research Program of the NIH, NINDS. 


\section{REFERENCES}

Allegrini, P. R., and Wiessner, C. (2003). Three-dimensional MRI of cerebral projections in rat brain in vivo after intracortical injection of $\mathrm{MnCl}_{2} . \mathrm{NMR}$ Biomed. 16, 252-256. doi: 10.1002/nbm.834

Alvestad, S., Goa, P. E., Qu, H., Risa, Ø., Brekken, C., Sonnewald, U., et al. (2007). In vivo mapping of temporospatial changes in manganese enhancement in rat brain during epileptogenesis. Neuroimage 38, 57-66. doi: 10.1016/j. neuroimage.2007.07.027

Aoki, I., Ebisu, T., Tanaka, C., Katsuta, K., Fujikawa, A., Umeda, M., et al. (2003). Detection of the anoxic depolarization of focal ischemia using manganeseenhanced MRI. Magn. Reson. Med. 50, 7-12. doi: 10.1002/mrm.10528

Aoki, I., Tanaka, C., Takegami, T., Ebisu, T., Umeda, M., Fukunaga, M., et al. (2002). Dynamic activity-induced manganese-dependent contrast magnetic resonance imaging (DAIM MRI). Magn. Reson. Med. 48, 927-933. doi: $10.1002 / \mathrm{mrm} .10320$

Aoki, I., Wu, Y. J., Silva, A. C., Lynch, R. M., and Koretsky, A. P. (2004). In vivo detection of neuroarchitecture in the rodent brain using manganese-enhanced MRI. Neuroimage 22, 1046-1059. doi: 10.1016/j.neuroimage.2004.03.031

Aschner, J. L., Anderson, A., Slaughter, J. C., Aschner, M., Steele, S., Beller, A., et al. (2015). Neuroimaging identifies increased manganese deposition in infants receiving parenteral nutrition. Am. J. Clin. Nutr. 102, 1482-1489. doi: 10.3945/ajcn.115.116285

Bacon, A. W., Bondi, M. W., Salmon, D. P., and Murphy, C. (1998). Very early changes in olfactory functioning due to Alzheimer's disease and the role of apolipoprotein E in olfaction. Ann. N Y Acad. Sci. 855, 723-731. doi: 10.1111/j. 1749-6632.1998.tb10651.x

Bearer, E. L., Manifold-Wheeler, B. C., Medina, C. S., Gonzales, A. G., Chaves, F. L., and Jacobs, R. E. (2018). Alterations of functional circuitry in aging brain and the impact of mutated APP expression. Neurobiol. Aging 70, 276-290. doi: 10.1016/j.neurobiolaging.2018.06.018

Berkowitz, B. A., Gradianu, M., Schafer, S., Jin, Y., Porchia, A., Iezzi, R., et al. (2008). Ionic dysregulatory phenotyping of pathologic retinal thinning with manganese-enhanced MRI. Invest. Ophthalmol. Vis. Sci. 49, 3178-3184. doi: 10.1167/iovs.08-1720

Berkowitz, B. A., Roberts, R., Goebel, D. J., and Luan, H. (2006). Noninvasive and simultaneous imaging of layer-specific retinal functional adaptation by manganese-enhanced MRI. Invest. Ophthalmol. Vis. Sci. 47, 2668-2674. doi: $10.1167 /$ iovs.05-1588

Bertrand, A., Khan, U., Hoang, D. M., Novikov, D. S., Krishnamurthy, P., Rajamohamed Sait, H. B., et al. (2013). Non-invasive, in vivo monitoring of neuronal transport impairment in a mouse model of tauopathy using MEMRI. Neuroimage 64, 693-702. doi: 10.1016/j.neuroimage.2012.08.065

Boretius, S., Gadjanski, I., Demmer, I., Bähr, M., Diem, R., Michaelis, T., et al. (2008). MRI of optic neuritis in a rat model. Neuroimage 41, 323-334. doi: 10.1016/j.neuroimage.2008.02.021

Brunnquell, C. L., Hernandez, R., Graves, S. A., Smit-Oistad, I., Nickles, R. J., Cai, W., et al. (2016). Uptake and retention of manganese contrast agents for PET and MRI in the rodent brain. Contrast Media. Mol. Imaging 11, 371-380. doi: $10.1002 / \mathrm{cmmi} .1701$

Calkins, D. J., Horner, P. J., Roberts, R., Gradianu, M., and Berkowitz, B. A. (2008). Manganese-enhanced MRI of the DBA/2J mouse model of hereditary glaucoma. Invest. Ophthalmol. Vis. Sci. 49, 5083-5088. doi: 10.1167/iovs.082205

Canals, S., Beyerlein, M., Keller, A. L., Murayama, Y., and Logothetis, N. K. (2008). Magnetic resonance imaging of cortical connectivity in vivo. Neuroimage 40, 458-472. doi: 10.1016/j.neuroimage.2007.12.007

Chan, K. C., Fu, Q. L., Hui, E. S., So, K. F., and Wu, E. X. (2008). Evaluation of the retina and optic nerve in a rat model of chronic glaucoma using in vivo manganese-enhanced magnetic resonance imaging. Neuroimage 40, 1166-1174. doi: 10.1016/j.neuroimage.2008.01.002

Chan, K. C., Zhou, I. Y., Liu, S. S., van der Merwe, Y., Fan, S. J., Hung, V. K., et al. (2017). Longitudinal assessments of normal and perilesional tissues in focal brain ischemia and partial optic nerve injury with manganese-enhanced MRI. Sci. Rep. 7:43124. doi: 10.1038/srep43124

Chandra, S. V., and Shukla, G. S. (1976). Role of iron deficiency in inducing susceptibility to manganese toxicity. Arch. Toxicol. 35, 319-323. doi: $10.1007 /$ bf00570272
Chen, C. C., Zechariah, A., Hsu, Y. H., Chen, H. W., Yang, L. C., and Chang, C. (2008). Neuroaxonal ion dyshomeostasis of the normal-appearing corpus callosum in experimental autoimmune encephalomyelitis. Exp. Neurol. 210, 322-330. doi: 10.1016/j.expneurol.2007.11.008

Chuang, K. H., and Koretsky, A. P. (2009). Accounting for nonspecific enhancement in neuronal tract tracing using manganese enhanced magnetic resonance imaging. Magn. Reson. Imaging 27, 594-600. doi: 10.1016/j.mri.2008. 10.006

Cosottini, M., Donatelli, G., Costagli, M., Caldarazzo Ienco, E., Frosini, D., Pesaresi, I., et al. (2016). High-resolution 7T MR imaging of the motor cortex in amyotrophic lateral sclerosis. Am. J. Neuroradiol. 37, 455-461. doi: 10.3174/ajnr.a4562

Cross, D. J., Minoshima, S., Anzai, Y., Flexman, J. A., Keogh, B. P., Kim, Y., et al. (2004). Statistical mapping of functional olfactory connections of the rat brain in vivo. Neuroimage 23, 1326-1335. doi: 10.1016/j.neuroimage.2004.07.038

Crossgrove, J., and Zheng, W. (2004). Manganese toxicity upon overexposure. NMR Biomed. 17, 544-553. doi: 10.1002/nbm.931

Dastur, D. K., Manghani, D. K., and Raghavendran, K. V. (1971). Distribution and fate of $54 \mathrm{Mn}$ in the monkey: studies of differnnt parts of the central nervous system and other organs. J. Clin. Invest. 50, 9-20. doi: 10.1172/jci 106487

Dedeurwaerdere, S., Fang, K., Chow, M., Shen, Y. T., Noordman, I., van Raay, L., et al. (2013). Manganese-enhanced MRI reflects seizure outcome in a model for mesial temporal lobe epilepsy. Neuroimage 68, 30-38. doi: 10.1016/j. neuroimage.2012.11.054

Duncan, J. S., Winston, G. P., Koepp, M. J., and Ourselin, S. (2016). Brain imaging in the assessment for epilepsy surgery. Lancet Neurol. 15, 420-433. doi: 10.1016/S1474-4422(15)00383-X

Eschenko, O., Canals, S., Simanova, I., Beyerlein, M., Murayama, Y., and Logothetis, N. K. (2010). Mapping of functional brain activity in freely behaving rats during voluntary running using manganese-enhanced MRI: implication for longitudinal studies. Neuroimage 49, 2544-2555. doi: 10.1016/j.neuroimage. 2009.10.079

Federle, M. P., Chezmar, J. L., Rubin, D. L., Weinreb, J. C., Freeny, P. C., Semelka, R. C., et al. (2000). Safety and efficacy of mangafodipir trisodium (MnDPDP) injection for hepatic MRI in adults: results of the U.S. multicenter phase III clinical trials (safety). J. Magn. Reson. Imaging 12, 186-197. doi: 10.1002/1522-2586(200011)12:5<689::aid-jmri5>3.0.co;2-Z

Fernandes, J. L., Storey, P., da Silva, J. A., de Figueiredo, G. S., Kalaf, J. M., and Coelho, O. R. (2011). Preliminary assessment of cardiac short term safety and efficacy of manganese chloride for cardiovascular magnetic resonance in humans. J. Cardiovasc. Magn. Reson. 13:6. doi: 10.1186/1532-429x-13-6

Fiedorowicz, M., Orzel, J., Kossowski, B., Welniak-Kaminska, M., Choragiewicz, T., Swiatkiewicz, M., et al. (2018). Anterograde transport in axons of the retinal ganglion cells and its relationship to the intraocular pressure during aging in mice with hereditary pigmentary glaucoma. Curr. Eye Res. 43, 539-546. doi: 10.1080/02713683.2017.1416147

Fontaine, S. N., Ingram, A., Cloyd, R. A., Meier, S. E., Miller, E., Lyons, D., et al. (2017). Identification of changes in neuronal function as a consequence of aging and tauopathic neurodegeneration using a novel and sensitive magnetic resonance imaging approach. Neurobiol. Aging 56, 78-86. doi: 10.1016/j. neurobiolaging.2017.04.007

Fukumura, S., Sasaki, M., Kataoka-Sasaki, Y., Oka, S., Nakazaki, M., Nagahama, H., et al. (2018). Intravenous infusion of mesenchymal stem cells reduces epileptogenesis in a rat model of status epilepticus. Epilepsy Res. 141, 56-63. doi: 10.1016/j.eplepsyres.2018.02.008

Gallagher, J. J., Zhang, X., Ziomek, G. J., Jacobs, R. E., and Bearer, E. L. (2012). Deficits in axonal transport in hippocampal-based circuitry and the visual pathway in APP knock-out animals witnessed by manganese enhanced MRI. Neuroimage 60, 1856-1866. doi: 10.1016/j.neuroimage.2012.01.132

Graves, S. A., Hernandez, R., Fonslet, J., England, C. G., Valdovinos, H. F., Ellison, P. A., et al. (2015). Novel preparation methods of (52)Mn for ImmunoPET imaging. Bioconjug. Chem. 26, 2118-2124. doi: 10.1021/acs. bioconjchem.5b00414

Hankir, M. K., Parkinson, J. R., Bloom, S. R., and Bell, J. D. (2012). The effects of glutamate receptor agonists and antagonists on mouse hypothalamic and hippocampal neuronal activity shown through manganese enhanced MRI. Neuroimage 59, 968-978. doi: 10.1016/j.neuroimage.2011.08.063 
Hao, X. Z., Yin, L. K., Zhang, X. X., Tian, J. Q., Li, C. C., Feng, X. Y., et al. (2016). Combining systemic and stereotactic MEMRI to detect the correlation between gliosis and neuronal connective pathway at the chronic stage after stroke. J. Neuroinflammation 13:156. doi: 10.1186/s12974-016-0622-7

Hardy, J., and Selkoe, D. J. (2002). The amyloid hypothesis of Alzheimer's disease: progress and problems on the road to therapeutics. Science 297, 353-356. doi: 10.1126/science.1072994

Hernandez, R., Graves, S. A., Gregg, T., VanDeusen, H. R., Fenske, R. J., Wienkes, H. N., et al. (2017). Radiomanganese PET detects changes in functional $\beta$-cell mass in mouse models of diabetes. Diabetes 66, 2163-2174. doi: $10.2337 / \mathrm{db} 16-1285$

Howles, G. P., Qi, Y., and Johnson, G. A. (2010). Ultrasonic disruption of the blood-brain barrier enables in vivo functional mapping of the mouse barrel field cortex with manganese-enhanced MRI. Neuroimage 50, 1464-1471. doi: $10.1016 /$ j.neuroimage.2010.01.050

Hsu, Y. H., Lee, W. T., and Chang, C. (2007). Multiparametric MRI evaluation of kainic acid-induced neuronal activation in rat hippocampus. Brain 130, 3124-3134. doi: 10.1093/brain/awm207

Immonen, R. J., Kharatishvili, I., Sierra, A., Einula, C., Pitkanen, A., and Grohn, O. H. (2008). Manganese enhanced MRI detects mossy fiber sprouting rather than neurodegeneration, gliosis or seizure-activity in the epileptic rat hippocampus. Front. Cell. Neurosci. 40, 1718-1730. doi: 10.1016/j.neuroimage. 2008.01.042

Jack, C. R. Jr., Shiung, M. M., Gunter, J. L., O’Brien, P. C., Weigand, S. D., Knopman, D. S., et al. (2004). Comparison of different MRI brain atrophy rate measures with clinical disease progression in AD. Neurology 62, 591-600. doi: 10.1212/01.wnl.0000110315.26026.ef

Jouroukhin, Y., Ostritsky, R., Assaf, Y., Pelled, G., Giladi, E., and Gozes, I. (2013). NAP (davunetide) modifies disease progression in a mouse model of severe neurodegeneration: protection against impairments in axonal transport. Neurobiol. Dis. 56, 79-94. doi: 10.1016/j.nbd.2013.04.012

Kam, K., Duffy, Á. M., Moretto, J., LaFrancois, J. J., and Scharfman, H. E. (2016). Interictal spikes during sleep are an early defect in the Tg2576 mouse model of $\beta$-amyloid neuropathology. Sci. Rep. 6:20119. doi: 10.1038/srep 20119

Kawai, Y., Aoki, I., Umeda, M., Higuchi, T., Kershaw, J., Higuchi, M., et al. (2010). In vivo visualization of reactive gliosis using manganese-enhanced magnetic resonance imaging. Neuroimage 49, 3122-3131. doi: 10.1016/j.neuroimage. 2009.11.005

Kerchner, G. A., Hess, C. P., Hammond-Rosenbluth, K. E., Xu, D., Rabinovici, G. D., Kelley, D. A., et al. (2010). Hippocampal CA1 apical neuropil atrophy in mild Alzheimer disease visualized with 7-T MRI. Neurology 75, 1381-1387. doi: 10.1212/WNL.0b013e3181f736al

Kikuta, S., Nakamura, Y., Yamamura, Y., Tamura, A., Homma, N., Yanagawa, Y., et al. (2015). Quantitative activation-induced manganese-enhanced MRI reveals severity of Parkinson's disease in mice. Sci. Rep. 5:12800. doi: 10.1038/ srep 12800

Kim, J., Choi, I. Y., Michaelis, M. L., and Lee, P. (2011). Quantitative in vivo measurement of early axonal transport deficits in a triple transgenic mouse model of Alzheimer's disease using manganese-enhanced MRI. Neuroimage 56, 1286-1292. doi: 10.1016/j.neuroimage.2011.02.039

Kwon, D. H., Kim, J. M., Oh, S. H., Jeong, H. J., Park, S. Y., Oh, E. S., et al. (2012). Seven-Tesla magnetic resonance images of the substantia nigra in Parkinson disease. Ann. Neurol. 71, 267-277. doi: 10.1002/ana.22592

Lee, J. H., Silva, A. C., Merkle, H., and Koretsky, A. P. (2005). Manganeseenhanced magnetic resonance imaging of mouse brain after systemic administration of $\mathrm{MnCl}_{2}$ : dose-dependent and temporal evolution of T1 contrast. Magn. Reson. Med. 53, 640-648. doi: 10.1002/mrm.20368

Leergaard, T. B., Bjaalie, J. G., Devor, A., Wald, L. L., and Dale, A. M. (2003). In vivo tracing of major rat brain pathways using manganese-enhanced magnetic resonance imaging and three-dimensional digital atlasing. Neuroimage 20, 1591-1600. doi: 10.1016/j.neuroimage.2003.07.009

Lehéricy, S., Bardinet, E., Poupon, C., Vidailhet, M., and François, C. (2014). 7 Tesla magnetic resonance imaging: a closer look at substantia nigra anatomy in Parkinson's disease. Mov. Disord. 29, 1574-1581. doi: 10.1002/mds.26043

Lin, T. H., Kim, J. H., Perez-Torres, C., Chiang, C. W., Trinkaus, K., Cross, A. H., et al. (2014). Axonal transport rate decreased at the onset of optic neuritis in EAE mice. Neuroimage 100, 244-253. doi: 10.1016/j.neuroimage.2014.06.009
Lin, Y. J., and Koretsky, A. P. (1997). Manganese ion enhances T1-weighted MRI during brain activation: an approach to direct imaging of brain function. Magn. Reson. Med. 38, 378-388. doi: 10.1002/mrm.1910380305

Livingstone, C. (2018). Manganese provision in parenteral nutrition: an update. Nutr. Clin. Pract. 33, 404-418. doi: 10.1177/0884533617702837

Luo, F., Rustay, N. R., Ebert, U., Hradil, V. P., Cole, T. B., Llano, D. A., et al. (2012). Characterization of 7- and 19-month-old Tg2576 mice using multimodal in vivo imaging: limitations as a translatable model of Alzheimer's disease. Neurobiol. Aging 33, 933-944. doi: 10.1016/j.neurobiolaging.2010.08.005

Lydén, A., Larsson, B. S., and Lindquist, N. G. (1983). Autoradiography of manganese: accumulation and retention in the pancreas. Acta Pharmacol. Toxicol. 52, 205-210. doi: 10.1111/j.1600-0773.1983.tb01087.x

Macdonald, I. R., DeBay, D. R., Reid, G. A., O'Leary, T. P., Jollymore, C. T., Mawko, G., et al. (2014). Early detection of cerebral glucose uptake changes in the 5XFAD mouse. Curr. Alzheimer Res. 11, 450-460. doi: 10.2174/1567205011666140505111354

Majid, T., Ali, Y. O., Venkitaramani, D. V., Jang, M. K., Lu, H. C., and Pautler, R. G. (2014). In vivo axonal transport deficits in a mouse model of fronto-temporal dementia. Neuroimage Clin. 4, 711-717. doi: 10.1016/j.nicl.2014.02.005

Malheiros, J. M., Persike, D. S., Castro, L. U., Sanches, T. R., Andrade Lda, C., Tannús, A., et al. (2014). Reduced hippocampal manganese-enhanced MRI (MEMRI) signal during pilocarpine-induced status epilepticus: edema or apoptosis? Epilepsy Res. 108, 644-652. doi: 10.1016/j.eplepsyres.2014.02.007

Malheiros, J. M., Polli, R. S., Paiva, F. F., Longo, B. M., Mello, L. E., Silva, A. C., et al. (2012). Manganese-enhanced magnetic resonance imaging detects mossy fiber sprouting in the pilocarpine model of epilepsy. Epilepsia 53, 1225-1232. doi: 10.1111/j.1528-1167.2012.03521.x

Martin, R. F., and Bowden, D. M. (2000). Primate Brain Maps: Structure of the Macaque Brain. Elsevier () 2000 University of Washington.

Merino, J. G., and Warach, S. (2010). Imaging of acute stroke. Nat. Rev. Neurol. 6, 560-571. doi: 10.1038/nrneurol.2010.129

Millecamps, S., and Julien, J. P. (2013). Axonal transport deficits and neurodegenerative diseases. Nat. Rev. Neurosci. 14, 161-176. doi: 10.1038/ nrn3380

Morita, H., Ogino, T., Seo, Y., Fujiki, N., Tanaka, K., Takamata, A., et al. (2002). Detection of hypothalamic activation by manganese ion contrasted $\mathrm{T}_{1}$ weighted magnetic resonance imaging in rats. Neurosci. Lett. 326, 101-104. doi: 10.1016/s0304-3940(02)00330-0

Mueller, S. G., Schuff, N., Yaffe, K., Madison, C., Miller, B., and Weiner, M. W. (2010). Hippocampal atrophy patterns in mild cognitive impairment and Alzheimer's disease. Hum. Brain Mapp. 31, 1339-1347. doi: 10.1002/hbm. 20934

Murayama, Y., Weber, B., Saleem, K. S., Augath, M., and Logothetis, N. K. (2006). Tracing neural circuits in vivo with Mn-enhanced MRI. Magn. Reson. Imaging 24, 349-358. doi: 10.1016/j.mri.2005.12.031

Nair, G., Pardue, M. T., Kim, M., and Duong, T. Q. (2011). Manganese-enhanced MRI reveals multiple cellular and vascular layers in normal and degenerated retinas. J. Magn. Reson. Imaging 34, 1422-1429. doi: 10.1002/jmri.22719

Nairismägi, J., Pitkanen, A., Narkilahti, S., Huttunen, J., Kauppinen, R. A., and Grohn, O. H. (2006). Manganese-enhanced magnetic resonance imaging of mossy fiber plasticity in vivo. Neuroimage 30, 130-135. doi: 10.1016/j. neuroimage.2005.09.007

Nanetti, L., Contarino, V. E., Castaldo, A., Sarro, L., Bachoud-Levi, A. C., Giavazzi, M., et al. (2018). Cortical thickness, stance control and arithmetic skill: an exploratory study in premanifest Huntington disease. Parkinsonism Relat. Disord. 51, 17-23. doi: 10.1016/j.parkreldis.2018.02.033

Napieczynska, H., Severin, G. W., Fonslet, J., Wiehr, S., Menegakis, A., Pichler, B. J., et al. (2017). Imaging neuronal pathways with (52) Mn PET: toxicity evaluation in rats. Neuroimage 158, 112-125. doi: 10.1016/j. neuroimage.2017.06.058

Nopoulos, P. C., Aylward, E. H., Ross, C. A., Johnson, H. J., Magnotta, V. A., Juhl, A. R., et al. (2010). Cerebral cortex structure in prodromal Huntington disease. Neurobiol. Dis. 40, 544-554. doi: 10.1016/j.nbd.2010.07.014

Olson, K. E., Bade, A. N., Schutt, C. R., Dong, J., Shandler, S. J., Boska, M. D., et al. (2016). Manganese-enhanced magnetic resonance imaging for detection of vasoactive intestinal peptide receptor 2 agonist therapy in a model of Parkinson's disease. Neurotherapeutics 13, 635-646. doi: 10.1007/s13311-016$0449-\mathrm{z}$ 
Olsen, O., Thuen, M., Berry, M., Kovalev, V., Petrou, M., Goa, P. E., et al. (2008). Axon tracing in the adult rat optic nerve and tract after intravitreal injection of MnDPDP using a semiautomatic segmentation technique. J. Magn. Reson. Imaging 27, 34-42. doi: 10.1002/jmri.21234

Palop, J. J., Chin, J., Roberson, E. D., Wang, J., Thwin, M. T., Bien-Ly, N., et al. (2007). Aberrant excitatory neuronal activity and compensatory remodeling of inhibitory hippocampal circuits in mouse models of Alzheimer's disease. Neuron 55, 697-711. doi: 10.1016/j.neuron.2007.07.025

Pautler, R. G., Mongeau, R., and Jacobs, R. E. (2003). In vivo trans-synaptic tract tracing from the murine striatum and amygdala utilizing manganese enhanced MRI (MEMRI). Magn. Reson. Med. 50, 33-39. doi: 10.1002/mrm.10498

Pautler, R. G., Silva, A. C., and Koretsky, A. P. (1998). In vivo neuronal tract tracing using manganese-enhanced magnetic resonance imaging. Magn. Reson. Med. 40, 740-748. doi: 10.1002/mrm.1910400515

Pelled, G., Bergman, H., Ben-Hur, T., and Goelman, G. (2007). Manganeseenhanced MRI in a rat model of Parkinson's disease. J. Magn. Reson. Imaging 26, 863-870. doi: $10.1002 /$ jmri.21051

Perez, P. D., Hall, G., Kimura, T., Ren, Y., Bailey, R. M., Lewis, J., et al. (2013). In vivo functional brain mapping in a conditional mouse model of human tauopathy (tauP301L) reveals reduced neural activity in memory formation structures. Mol. Neurodegener. 8:9. doi: 10.1186/1750-1326-8-9

Poisnel, G., Hérard, A. S., El Tayara, N. E., Bourrin, E., Volk, A., Kober, F., et al. (2012). Increased regional cerebral glucose uptake in an APP/PS1 model of Alzheimer's disease. Neurobiol. Aging 33, 1995-2005. doi: 10.1016/j. neurobiolaging.2011.09.026

Quaghebeur, G., Taylor, W. J., Kingsley, D. P. E., Fell, J. M. E., Reynolds, A. P., and Milla, P. J. (1996). MRI in children receiving total parenteral nutrition. Neuroradiology 38, 680-683. doi: 10.1007/s002340050333

Reich, D. S., Lucchinetti, C. F., and Calabresi, P. A. (2018). Multiple sclerosis. N. Engl. J. Med. 378, 169-180. doi: 10.1056/NEJMra1401483

Ridha, B. H., Anderson, V. M., Barnes, J., Boyes, R. G., Price, S. L., Rossor, M. N., et al. (2008). Volumetric MRI and cognitive measures in Alzheimer disease : comparison of markers of progression. J. Neurol. 255, 567-574. doi: 10.1007/s00415-008-0750-9

Ross, C. A., Aylward, E. H., Wild, E. J., Langbehn, D. R., Long, J. D., Warner, J. H., et al. (2014). Huntington disease: natural history, biomarkers and prospects for therapeutics. Nat. Rev. Neurol. 10, 204-216. doi: 10.1038/nrneurol.2014.24

Saar, G., Cheng, N., Belluscio, L., and Koretsky, A. P. (2015). Laminar specific detection of APP induced neurodegeneration and recovery using MEMRI in an olfactory based Alzheimer's disease mouse model. Neuroimage 118, 183-192. doi: 10.1016/j.neuroimage.2015.05.045

Saar, G., Millo, C. M., Szajek, L. P., Bacon, J., Herscovitch, P., and Koretsky, A. P. (2018). Anatomy, functionality and neuronal connectivity with manganese radiotracers for positron emission tomography. Mol. Imaging Biol. 20, 562-574. doi: 10.1007/s11307-018-1162-6

Saleem, K. S., Pauls, J. M., Augath, M., Trinath, T., Prause, B. A., Hashikawa, T., et al. (2002). Magnetic resonance imaging of neuronal connections in the macaque monkey. Neuron 34, 685-700. doi: 10.1016/s0896-6273(02)00718-3

Schima, W., Függer, R., Schober, E., Oettl, C., Wamser, P., Grabenwoger, F., et al. (2002). Diagnosis and staging of pancreatic cancer: comparison of mangafodipir trisodium-enhanced MR imaging and contrast-enhanced helical hydro-CT. AJR Am. J. Roentgenol. 179, 717-724. doi: 10.2214/ajr.179.3.1790717

Silva, A. C., Lee, J. H., Aoki, L., and Koretsky, A. R. (2004). Manganeseenhanced magnetic resonance imaging (MEMRI): methodological and practical considerations. NMR Biomed. 17, 532-543. doi: 10.1002/nbm.945

Silva, A. C., Lee, J. H., Wu, C. W., Tucciarone, J., Pelled, G., Aoki, I., et al. (2008). Detection of cortical laminar architecture using manganese-enhanced MRI. J. Neurosci. Methods 167, 246-257. doi: 10.1016/j.jneumeth.2007.08.020

Skjold, A., Amundsen, B. H., Wiseth, R., Støylen, A., Haraldseth, O., Larsson, H. B., et al. (2007). Manganese dipyridoxyl-diphosphate (MnDPDP) as a viability marker in patients with myocardial infarction. J. Magn. Reson. Imaging 26, 720-727. doi: $10.1002 /$ jmri.21065

Sloot, W. N., and Gramsbergen, J. B. (1994). Axonal transport of manganese and its relevance to selective neurotoxicity in the rat basal ganglia. Brain Res. 657, 124-132. doi: 10.1016/0006-8993(94)90959-8

Smith, K. D., Kallhoff, V., Zheng, H., and Pautler, R. G. (2007). In vivo axonal transport rates decrease in a mouse model of Alzheimer's disease. Neuroimage 35, 1401-1408. doi: 10.1016/j.neuroimage.2007.01.046
Smith, K. D., Paylor, R., and Pautler, R. G. (2011). R-flurbiprofen improves axonal transport in the Tg2576 mouse model of Alzheimer's disease as determined by MEMRI. Magn. Reson. Med. 65, 1423-1429. doi: 10.1002/mrm.22733

Smith, K. D., Peethumnongsin, E., Lin, H., Zheng, H., and Pautler, R. G. (2010). Increased human wildtype tau attenuates axonal transport deficits caused by loss of APP in mouse models. Magn. Reson. Insights 4, 11-18. doi: 10.4137/ MRI.S5237

Soria, G., Aguilar, E., Tudela, R., Mullol, J., Planas, A. M., and Marin, C. (2011). In vivo magnetic resonance imaging characterization of bilateral structural changes in experimental Parkinson's disease: a T2 relaxometry study combined with longitudinal diffusion tensor imaging and manganese-enhanced magnetic resonance imaging in the 6-hydroxydopamine rat model. Eur. J. Neurosci. 33, 1551-1560. doi: 10.1111/j.1460-9568.2011.07639.x

Sourani, D., Eitan, R., Gordon, N., and Goelman, G. (2012). The habenula couples the dopaminergic and the serotonergic systems: application to depression in Parkinson's disease. Eur. J. Neurosci. 36, 2822-2829. doi: 10.1111/j.1460-9568. 2012.08200.x

Sudarshana, D., Nair, G., Dwyer, J., Dewey, B., Steele, S. U., Cortese, I. C. M., et al. (2018). Manganese-enhanced MRI (MEMRI) of the brain in humans. Abstract, American Society of Neuroradiology, 56th annual meeting, Vancouver, BC.

Takeda, A., Kodama, Y., Ishiwatari, S., and Okada, S. (1998). Manganese transport in the neural circuit of rat CNS. Brain Res. Bull. 45, 149-152. doi: 10.1016/s0361-9230(97)00330-4

Tang, X., Holland, D., Dale, A. M., Younes, L., Miller, M. I., and Alzheimer's Disease Neuroimaging Initiative. (2014). Shape abnormalities of subcortical and ventricular structures in mild cognitive impairment and Alzheimer's disease: detecting, quantifying and predicting. Hum. Brain Mapp. 35, 3701-3725. doi: 10.1002/hbm.22431

Tang, X., Wu, D., Gu, L. H., Nie, B. B., Qi, X. Y., Wang, Y. J., et al. (2016). Spatial learning and memory impairments are associated with increased neuronal activity in 5XFAD mouse as measured by manganese-enhanced magnetic resonance imaging. Oncotarget 7, 57556-57570. doi: 10.18632/oncotarget. 11353

Thomann, P. A., Dos Santos, V., Toro, P., Schonknecht, P., Essig, M., and Schroder, J. (2009). Reduced olfactory bulb and tract volume in early Alzheimer's disease-a MRI study. Neurobiol. Aging 30, 838-841. doi: 10.1016/j. neurobiolaging.2007.08.001

Thompson, P. M., Hayashi, K. M., De Zubicaray, G. I., Janke, A. L., Rose, S. E., Semple, J., et al. (2004). Mapping hippocampal and ventricular change in Alzheimer disease. Neuroimage 22, 1754-1766. doi: 10.1016/j.neuroimage. 2004.03 .040

Tjälve, H., Henriksson, J., Tallkvist, J., Larsson, B. S., and Lindquist, N. G. (1996). Uptake of manganese and cadmium from the nasal mucosa into the central nervous system via olfactory pathways in rats. Pharmacol. Toxicol. 79, 347-356. doi: 10.1111/j.1600-0773.1996.tb00021.x

Tofts, P. S., Porchia, A., Jin, Y., Roberts, R., and Berkowitz, B. A. (2010). Toward clinical application of manganese-enhanced MRI of retinal function. Brain Res. Bull. 81, 333-338. doi: 10.1016/j.brainresbull.2009.06.002

Topping, G. J., Schaffer, P., Hoehr, C., Ruth, T. J., and Sossi, V. (2013). Manganese52 positron emission tomography tracer characterization and initial results in phantoms and in vivo. Med. Phys. 40:042502. doi: 10.1118/1.4793756

Traboulsee, A., Simon, J. H., Stone, L., Fisher, E., Jones, D. E., Malhotra, A., et al. (2016). Revised recommendations of the consortium of ms centers task force for a standardized MRI protocol and clinical guidelines for the diagnosis and follow-up of multiple sclerosis. Am. J. Neuroradiol. 37, 394-401. doi: 10.3174/ajnr.a4539

Tucciarone, J., Chuang, K. H., Dodd, S. J., Silva, A., Pelled, G., and Koretsky, A. P. (2009). Layer specific tracing of corticocortical and thalamocortical connectivity in the rodent using manganese enhanced MRI. Neuroimage 44, 923-931. doi: 10.1016/j.neuroimage.2008.07.036

Van der Linden, A., Verhoye, M., Van Meir, V., Tindemans, I., Eens, M., Absil, P., et al. (2002). In vivo manganese-enhanced magnetic resonance imaging reveals connections and functional properties of the songbird vocal control system. Neuroscience 112, 467-474. doi: 10.1016/s0306-4522(02)00070-2

van der Zijden, J. P., Bouts, M. J., Wu, O., Roeling, T. A., Bleys, R. L., van der Toorn, A., et al. (2008). Manganese-enhanced MRI of brain plasticity in relation to functional recovery after experimental stroke. J. Cereb. Blood Flow Metab. 28, 832-840. doi: $10.1038 /$ sj.jcbfm. 9600576 
van der Zijden, J. P., Wu, O., van der Toorn, A., Roeling, T. P., Bleys, R. L., and Dijkhuizen, R. M. (2007). Changes in neuronal connectivity after stroke in rats as studied by serial manganese-enhanced MRI. Neuroimage 34, 1650-1657. doi: 10.1016/j.neuroimage.2006.11.001

van Meer, M. P., van der Marel, K., Otte, W. M., Berkelbach van der Sprenkel, J. W., and Dijkhuizen, R. M. (2010). Correspondence between altered functional and structural connectivity in the contralesional sensorimotor cortex after unilateral stroke in rats: a combined resting-state functional MRI and manganese-enhanced MRI study. J. Cereb. Blood Flow Metab. 30, 1707-1711. doi: $10.1038 /$ jcbfm.2010.124

Wang, F. H., Appelkvist, P., Klason, T., Gissberg, O., Bogstedt, A., Eliason, K., et al. (2012). Decreased axonal transport rates in the Tg2576 APP transgenic mouse: improvement with the $\gamma$-secretase inhibitor MRK- 560 as detected by manganese-enhanced MRI. Eur. J. Neurosci. 36, 3165-3172. doi: 10.1111/j. 1460-9568.2012.08258.x

Wang, C., Gordon, P. B., Hustvedt, S. O., Grant, D., Sterud, A. T., Martinsen, I., et al. (1997). MR imaging properties and pharmacokinetics of MnDPDP in healthy volunteers. Acta Radiol. 38, 665-676. doi: 10.1080/02841859709172399

Wang, J., You, H., Liu, J. F., Ni, D. F., Zhang, Z. X., and Guan, J. (2011). Association of olfactory bulb volume and olfactory sulcus depth with olfactory function in patients with Parkinson disease. Am. J. Neuroradiol. 32, 677-681. doi: 10.3174/ajnr.A2350

Watanabe, T., Michaelis, T., and Frahm, J. (2001). Mapping of retinal projections in the living rat using high-resolution 3D gradient-echo MRI with $\mathrm{Mn}^{2+}$-induced contrast. Magn. Reson. Med. 46, 424-429. doi: 10.1002/ mrm. 1209

Watanabe, T., Natt, O., Boretius, S., Frahm, J., and Michaelis, T. (2002). In vivo 3D MRI staining of mouse brain after subcutaneous application of $\mathrm{MnCl}_{2}$. Magn. Reson. Med. 48, 852-859. doi: 10.1002/mrm.10276

Weng, J. C., Tikhonova, M. A., Chen, J. H., Shen, M. S., Meng, W. Y., Chang, Y. T., et al. (2016). Ceftriaxone prevents the neurodegeneration and decreased neurogenesis seen in a Parkinson's disease rat model: an immunohistochemical and MRI study. Behav. Brain Res. 305, 126-139. doi: 10.1016/j.bbr.2016. 02.034
Wesson, D. W., Levy, E., Nixon, R. A., and Wilson, D. A. (2010). Olfactory dysfunction correlates with amyloid- $\beta$ burden in an Alzheimer's disease mouse model. J. Neurosci. 30, 505-514. doi: 10.1523/JNEUROSCI.4622-09.2010

Wisse, L. E., Biessels, G. J., Heringa, S. M., Kuijf, H. J., Koek, D. H., Luijten, P. R., et al. (2014). Hippocampal subfield volumes at $7 \mathrm{~T}$ in early Alzheimer's disease and normal aging. Neurobiol. Aging 35, 2039-2045. doi: 10.1016/j. neurobiolaging.2014.02.021

Wolf, G. L., and Baum, L. (1983). Cardiovascular toxicity and tissue proton T1 response to manganese injection in the dog and rabbit. AJR Am. J. Roentgenol. 141, 193-197. doi: 10.2214/ajr.141.1.193

Yang, X. L., van der Merwe, Y., Sims, J., Parra, C., Ho, L. C., Schuman, J. S., et al. (2018). Age-related Changes in eye, brain and visuomotor behavior in the DBA/2J mouse model of chronic glaucoma. Sci. Rep. 8:4643. doi: 10.1038/s41598-018-22850-4

Yoo, A. J., Verduzco, L. A., Schaefer, P. W., Hirsch, J. A., Rabinov, J. D., and Gonzalez, R. G. (2009). MRI-based selection for intra-arterial stroke therapy: value of pretreatment diffusion-weighted imaging lesion volume in selecting patients with acute stroke who will benefit from early recanalization. Stroke 40, 2046-2054. doi: 10.1161/STROKEAHA.108.541656

Yu, X., Zou, J., Babb, J. S., Johnson, G., Sanes, D. H., and Turnbull, D. H. (2008). Statistical mapping of sound-evoked activity in the mouse auditory midbrain using Mn-enhanced MRI. Neuroimage 39, 223-230. doi: 10.1016/j.neuroimage. 2007.08.029

Conflict of Interest Statement: The authors declare that the research was conducted in the absence of any commercial or financial relationships that could be construed as a potential conflict of interest.

Copyright (c) 2019 Saar and Koretsky. This is an open-access article distributed under the terms of the Creative Commons Attribution License (CC BY). The use, distribution or reproduction in other forums is permitted, provided the original author(s) and the copyright owner(s) are credited and that the original publication in this journal is cited, in accordance with accepted academic practice. No use, distribution or reproduction is permitted which does not comply with these terms. 